\title{
3D DIGITAL MODEL DATABASE APPLIED TO CONSERVATION AND RESEARCH OF WOODEN CONSTRUCTION IN CHINA
}

\author{
Yu ZHENG
}

Cultural Heritage Conservation Centre (CHCC), Beijing Tsinghua TongHeng Urban Planning \& Design Institute, Beijing, China blizza@chcc.org.cn

KEY WORDS: Wooden Construction, Recording, Information Inventory, 3D Digital Model Database

\begin{abstract}
:
Protected by the Tai-Hang Mountains, Shanxi Province, located in north central China, is a highly prosperous, densely populated valley and considered to be one of the cradles of Chinese civilization. Its continuous habitation and rich culture have given rise to a large number of temple complexes and pavilions. Among these structures, 153 can be dated as early as from the Tang dynasty (618907C.E.) to the end of the Yuan dynasty (1279-1368C.E.) in Southern Shanxi area. The buildings are the best-preserved examples of wooden Chinese architecture in existence, exemplifying historic building technology and displaying highly intricate architectural decoration and detailing. They have survived war, earthquakes, and, in the last hundred years, neglect. In 2005, a decade-long conservation project was initiated by the State Administration of Cultural Heritage of China (SACH) to conserve and document these important buildings.
\end{abstract}

The conservation process requires stabilization, conservation of important features, and, where necessary, partial dismantlement in order to replace unsound structural elements. Project team of CHCC have developed a practical recording system that created a record of all building components prior to and during the conservation process. After that we are trying to establish a comprehensive database which include all of the 153 earlier buildings, through which we can easily entering, browse, indexing information of the wooden construction, even deep into component details. The Database can help us to carry out comparative studies of these wooden structures, and, provide important support for the continued conservation of these heritage buildings.

For some of the most important wooden structure, we have established three-dimensional models. Connected the Database with 3D Digital Model based on ArcGIS, we have developed 3D Digital Model Database for these cherish buildings. The 3D Digital Model Database helps us set up an integrate information inventory for wooden structure with their similar types in China, and; makes it much easier to carry out survey of these structures at any stage for the purpose of structure monitor. Large amounts of data in the wooden structure can be intuitively expressed graphically to show its spatial distribution; and we can make comprehensive assessment of the component group by observe the spatial pattern, or evaluate the whole building damage through the database. The most interesting is that, with the development of mobile terminal equipment, the 3D Digital Model Database of Wooden Structure can be displayed in virtual exhibition easily via the internet by them.

\section{CONSERVATION OF THE EARLY WOODEN CONSTRUCTION IN SOUTHERN SHANXI, CHINA}

Chinese architecture made of wood has a limited life; buildings constructed before the end of the Yuan Dynasty (1367 A.D) are extremely rare, highly valuable and officially classified as 'Early Construction.' These 'Early Construction' buildings are important physical examples of Chinese history through architecture. Highly developed arts and crafts complement these buildings through skilful construction and elaborate architectural decoration and detailing, making them vivid examples of Chinese civilization development.

The dry continental climate in Shanxi helped preserve these buildings for hundreds of years; however wars in recent history and poverty disrupted maintenance. Many of these buildings are suffering from structural failure, partially collapsed roofs and walls, sinking foundations, leaning columns and twisted beams. The furnishings, decorations and sculptures of the buildings have decayed with many pieces missing or damaged.

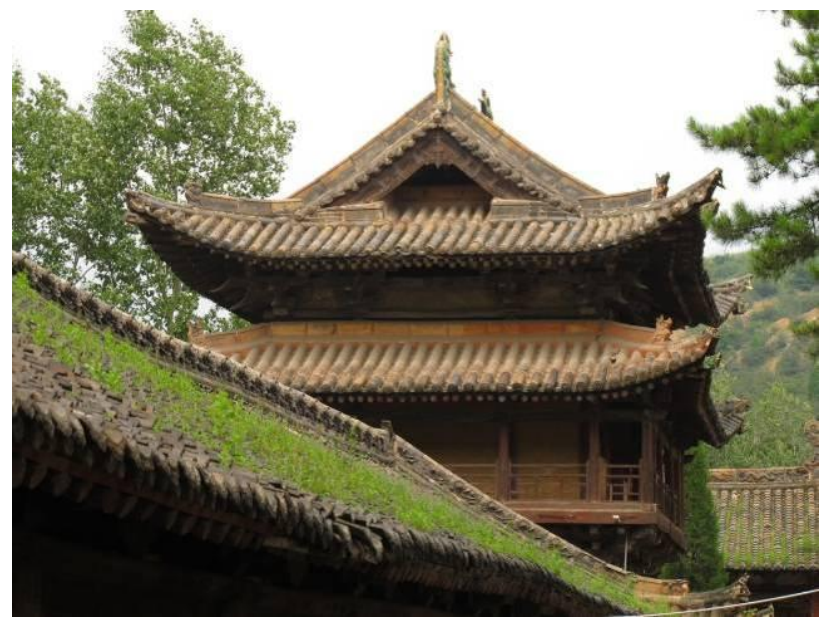

Figure 1 Xi Shu Zhuang Pavilion date to Jin Dynasty (11151234A.D.) in Lingchuan County, Shanxi Province. Being renovated before 2005 . 
Emergency rescue conservation projects occurred in recent decades but were inadequate to address all the issues or save all of the structures. In 2005, the State Administration of Cultural Heritage of China $(\mathrm{SACH})$ launched a comprehensive project for conservation of all the sites with pre-Yuan Dynasty buildings. This action named Conservation of the Early Wooden Construction in Southern Shanxi (CECSS) involves 105 nationally protected sites with more than 2,000 heritage buildings of which 153 are of Early Wooden Construction. It also involves 49 counties and four municipal governments. In the CECSS project, all major licensed architecture conservation firms from across north China were also invited to participate.

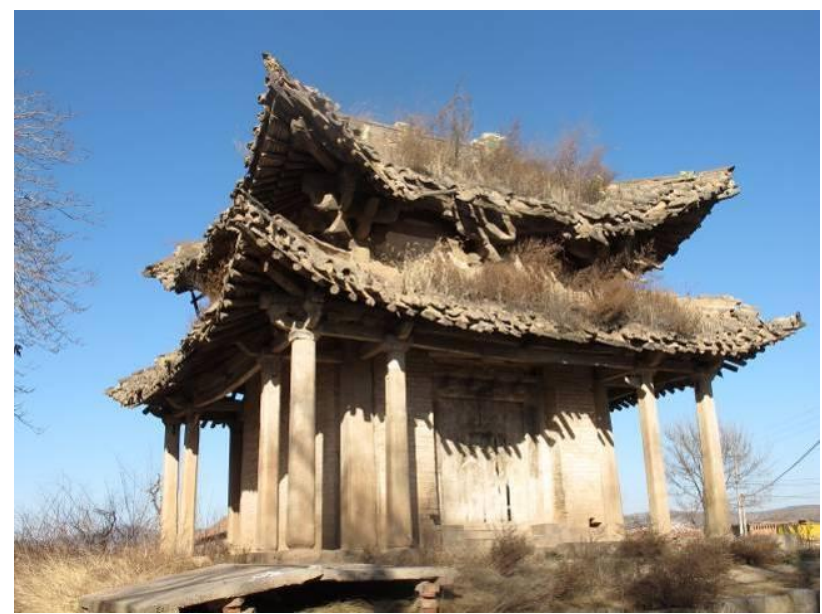

Figure 2 Sirun Sanjiao Tang date to Jin Dynasty (1115-1234 A.D.) in Lingchuan County, Shanxi Province. Not being renovated form the end of Qing Dynasty(1911 A.D.)

With so many heritage buildings, different levels of government and numerous architectural firms, it was essential to closely coordinate conservation and documentation; because valuable historical evidence is often discovered under roofing or hidden within walls of the structures, traces of earlier interventions are also buried within the structures. More importantly, any changes made to the original structures during intervention may interfere with their authenticity. To minimize any negative impact, including methods and reasons for changes had to be carefully documented in sufficient detail. In order to document the uncovered information during conservation along with detailed work during implementation, a clear, easy-tounderstand process had to be created.

\section{RECORDING SYSTEM FOR IMPLEMENTATION PROCESS}

A recording implementation process was created to document these important historic constructions during conservation. It was adapted to the capacity of the workers and placed special emphasis on gathering information that would not be retrievable after the completion of the intervention. This process consisted of a detailed flowchart that identified who was responsible for the documentation at every phase of the work, an easy to follow methodology on how to conduct the documentation, and a training program to improve the skill and understanding of the workers. The training program included why this documentation was necessary and important, various methods of recording and instructions in using the flowchart.
The documentation was broken down into the same set of phases and tasks that mirrored the conservation work. The team simply used Microsoft $(\mathcal{C}$ Office Project to create the Flowchart which included a timeline of the phases and inventory of all the tasks. Each task's name, number, person responsible and sequence were listed. Hyperlinks next to the task name lead to detailed Project Documentation Form. This entire flowchart served as a visual table of content to all the detailed documentation material and also assisted in management of the conservation work.

As the tasks were followed during conservation, detailed technical information and descriptive information was entered into the Project Documentation Form. These forms were generated to fully describe the different nature of each task. Each form was made of two parts - a cover page and a series of attachments. The cover page contain general description of the task, task number, a written condition assessment before, during and after each task, and links to all associated background files, attachments and images. In addition all parties, including implementation and inspection companies were listed by name and include the signatures of the recorder and inspectors - this ensured that responsibilities were clear. The series of attachments include more detailed information of the architectural members, conservation techniques and procedures, illustrated reports, images and measured drawings. They also include information on quantity, size and condition of individual architectural members. Important images illustrating key procedures or discoveries were inserted directly into attachments with descriptive text. Other images such as those used to describe a process were not included in the attachment but placed into a directory and hyperlinked.

Data is stored in the computer in site offices and backed up on a daily basis. It is then periodically collected and backed up by an assigned inspector responsible for multiple sites. The data is organized into a directory structure first by site name, then by each building. In the building folder, information is categorized into three subfolders: task records, related material, and images. The task records folder contains the task list Flowchart and the Project Documentation Forms. The related material folder has attachments, technical reports, site inspection dairy and notes, and other disclosure records. The images folder stores thousands of images in subfolders sorted by shooting date.

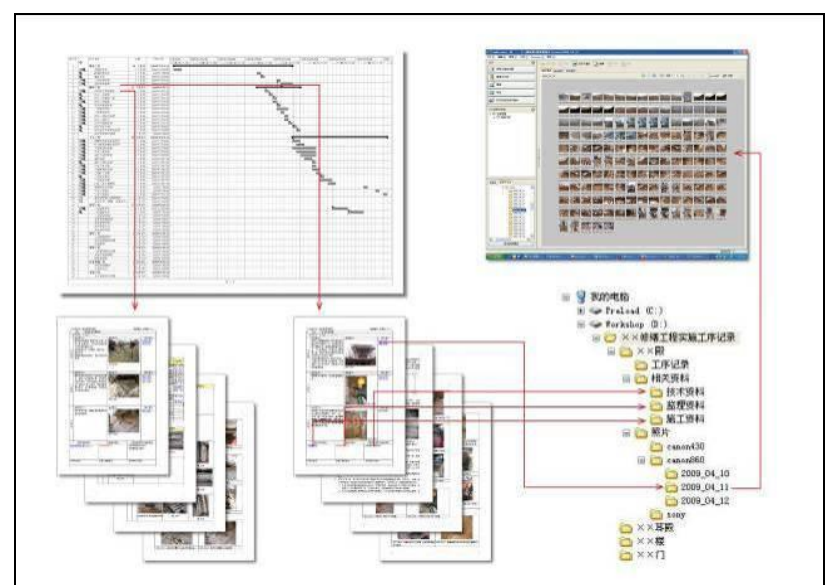

Figure 3 Data structure showing the links between the flowchart and Project Documentation Form as well as additional images. The directory structure was important in order to accommodate the massive amount of data and images. 


\section{DATABASE FOR EARLY WOODEN CONSTRUCTION}

Now in the second phase of the CECSS documentation project, the new focus is to review and check the collected information. A comprehensive Database is established including all of the 153 earlier buildings. In this Database, all information collected in implementation process is stored in data format in-stead of archival material. Information is attribute of substantial object, and substantial object bearing information as attribute of them. The Early Wooden Construction contains a lot of information which is important to research, interpretation and conservation. But different information corresponds to different level of substantial object in wooden construction. Given the present needs, we divided a wooden construction into three levels of substantial object. The whole building is regarded as one substantial object on the top level; independent functional groups consist of various construction members are middle level object; and construction members that cannot be divided are bottom level of substantial object.

Different level of substantial object corresponds different information as attribute. In the construction level, the whole wooden construction be regarded as one substantial object, we can find macroscopically information including name of the building, building identity number, name of heritage site, building profiles, photos, and construction full view picture; as well as age of the building, architectural function, architectural type, worship content, subsidiary artworks, building construction type, building orientation and other characteristics of information. Each piece of information is a certain attribute value for a certain wooden construction. For example, "age of the building" attribute item, there may be Tang Dynasty(618907A.D.), Five Dynasties and Ten States(907-979 A.D.), Northern Song Dynasty(960-1127 A.D.), Jin Dynasty(11271234A.D.) etc.

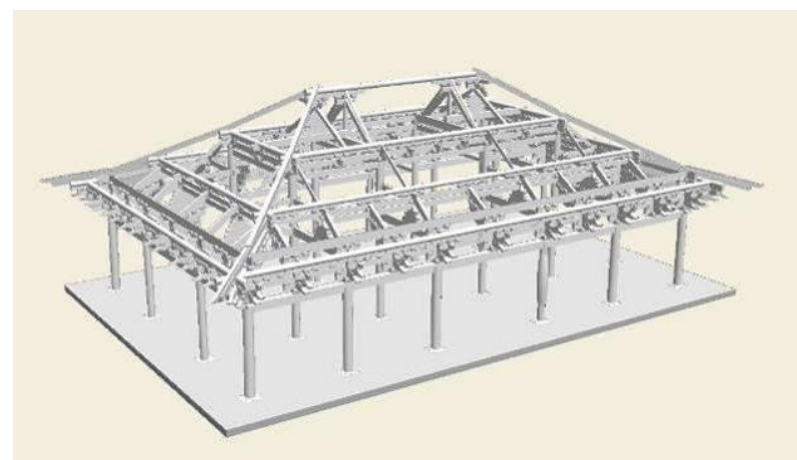

Figure 4 The whole wooden construction be regard as one object.

In the groups level, we divided the whole wooden construction into several parts such as platform, column grid, brackets which we called "dou gong", trusses, roofs and so on. For some group type, there is only one in a whole wooden structure, just as there is only one platform in a building. But there are several groups on certain group type. For example, there maybe ten to twenty set of "dou gong" in one wooden structure. So we need a coding system to ensure each group has an unique identity number. Some information is uniform for all the groups, but some information is different by types of group. We have set up the common information for groups such as group name, type, age, profiles and photos, and also characteristic information which are important for comparative studies. For example, "section of dou gong" attribute item is important information which reveals age features of the construction.

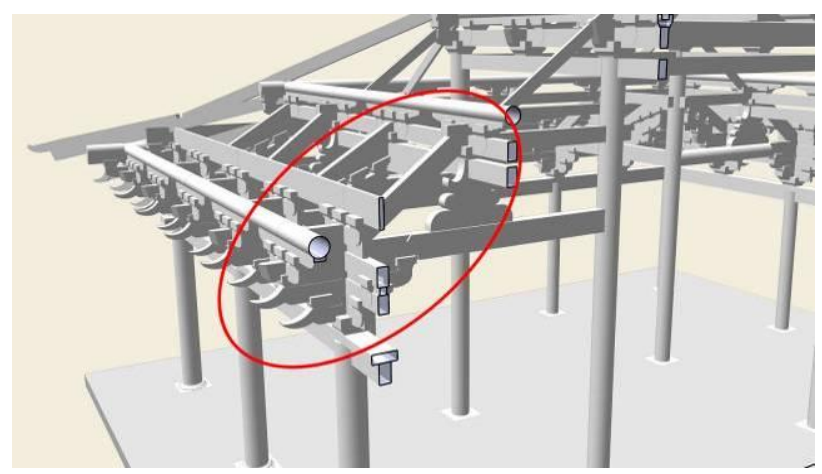

Figure 5 Brackets we called "dou gong" are consist of a group of component. It transmit gravity force of roof to column.

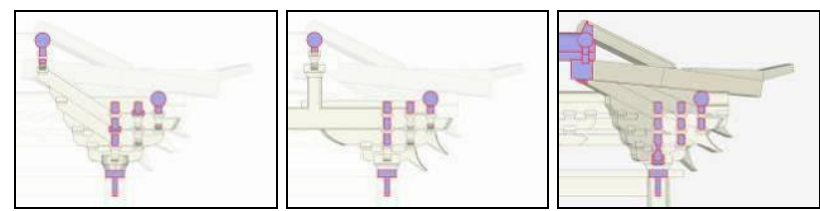

Figure 6 Section of "dou gong" with different kind in a wooden construction.

In the component level, we concern on much more detailed information for each construction member. We set up length, width, thickness and diameter data items to define physical dimension of component, and also material data items as wood species and sample code. We define shape characteristic and processing technical data items for each component. For example, there is a kind of construction member named "ang" in "dou gong" group which is a balance lever. The tip of "ang" has different shape but we can conclude them into two kinds typologically, one is a straight slope called "pi zhu ang" and the other is a gently curved arc called "qin mian ang". The "pi zhu ang" is appeared earlier than "qin mian ang" in wooden construction in China. But they co-exist for a long period of time especially in Song and Jin dynasty. We set up this data item in the database to help better understand of these heritage building.

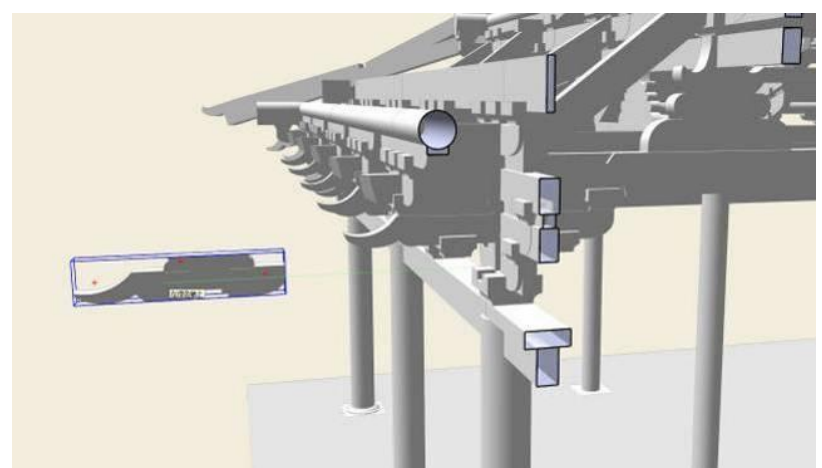

Figure 7 A construction member in group of "dou gong".

We use Microsoft (C SQL Server to set up the database of wooden construction in southern Shanxi province. Through this database, we can easily input, browse, index and query huge information of wooden construction heritage. We have planned four function pages when open the database. The first page is template editor. On this page we set up an integrity data 


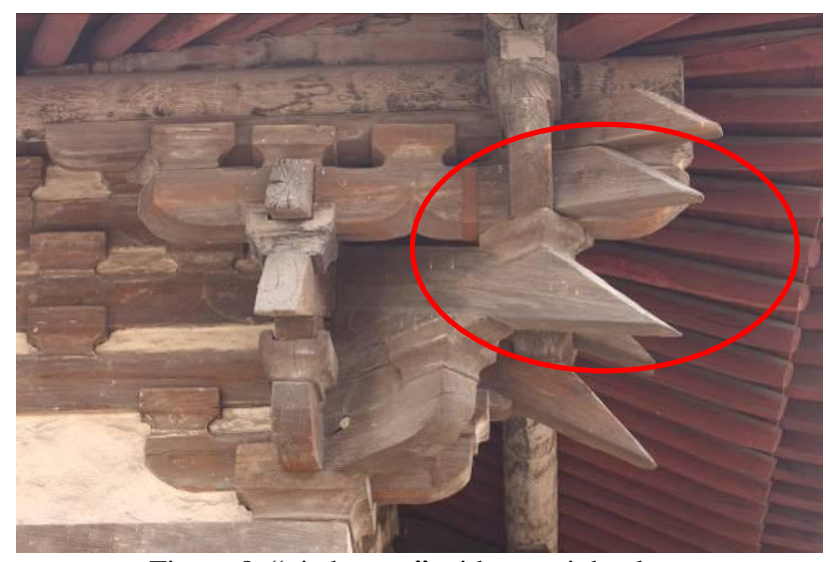

Figure 8 "pi zhu ang” with a straight slope

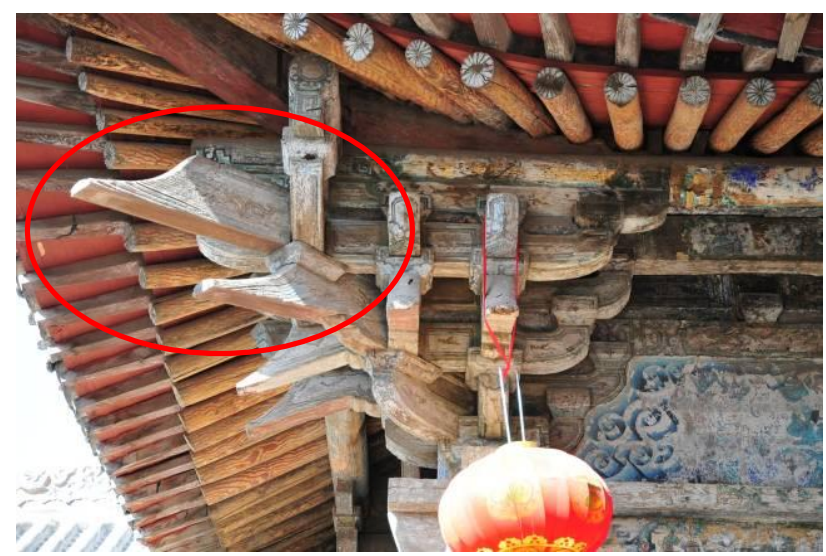

Figure 9 "qin mian ang" with a gently curved arc

structure of wooden construction which included all kinds of information. The second is data input page. We can create a wooden construction sub-database following the template we have set up, then hiding some data items away that do not exist in this building. After that we can input values of data items into the database on this page. The third page is for browse use. It is a reverse of input page, from this page we can seek information we need according to the tree-shape structure of the database. The fourth is an index and query page. On this page we can set some conditions to query into the database and find out which building have identical data meeting the conditions, and list out related information for comparative study.

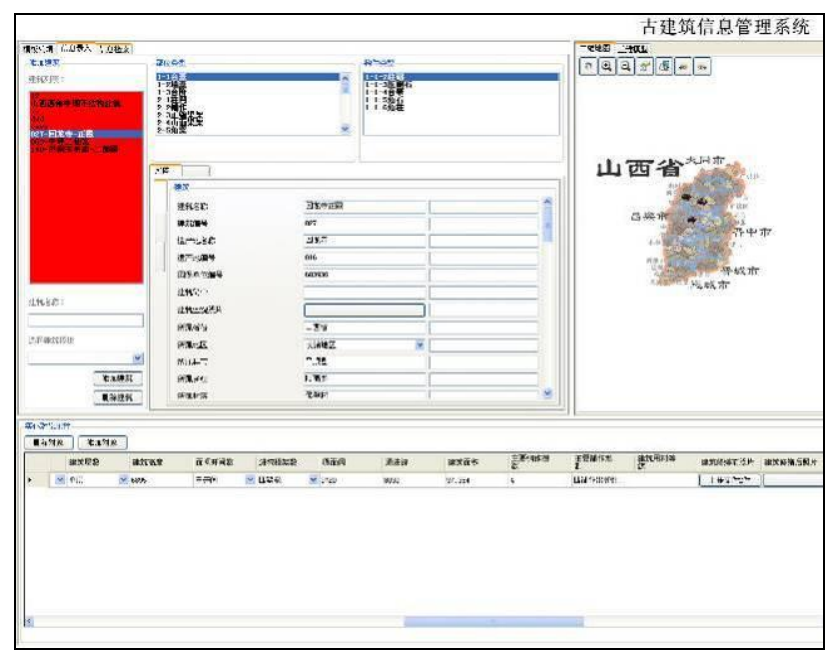

Figure 10 Database for Early Wooden Construction, data input page.
For example, there are a series of connecting beams circled on the top of column grid and we can find the beam head comes out at the corner. We find some of the beam head are just decorative "head" but are not connected with any real beams. We have set a data item to describe this phenomenon in group of column gird. So we can query into the database to list out all of the wooden construction which have the decorative head. Then we add these buildings age and geographical information into the list. We can find that most of these building concentrated in the southeast of Shanxi province, and they appeared between later period of Song dynasty and middle period of Jin dynasty. When we going into further analysis about the phenomenon, we can find it was influenced by the central area of China at that time which was the capital and cultural center of whole empire.

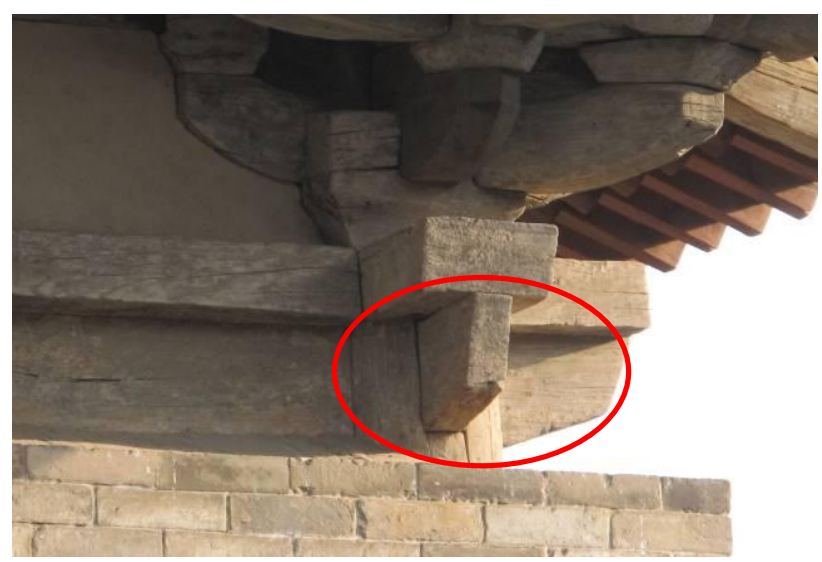

Figure 11 beam head comes out at the corner

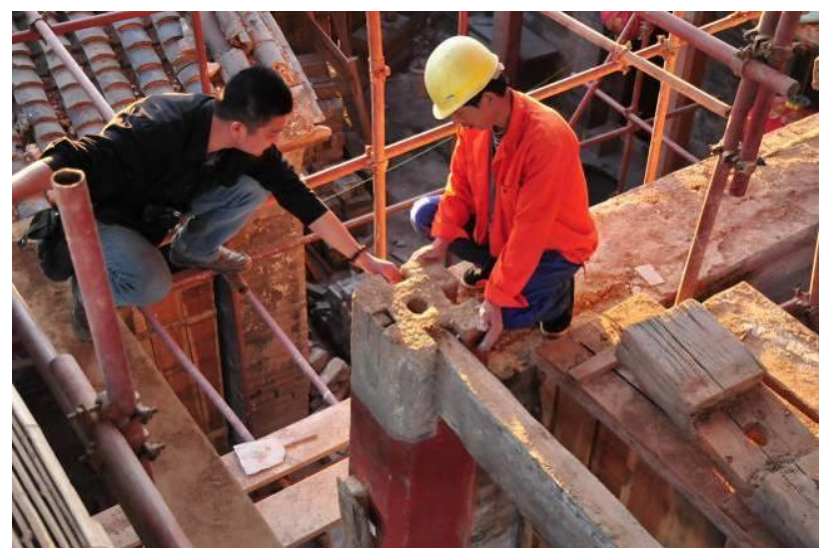

Figure 12 beam not really comes out at the corner

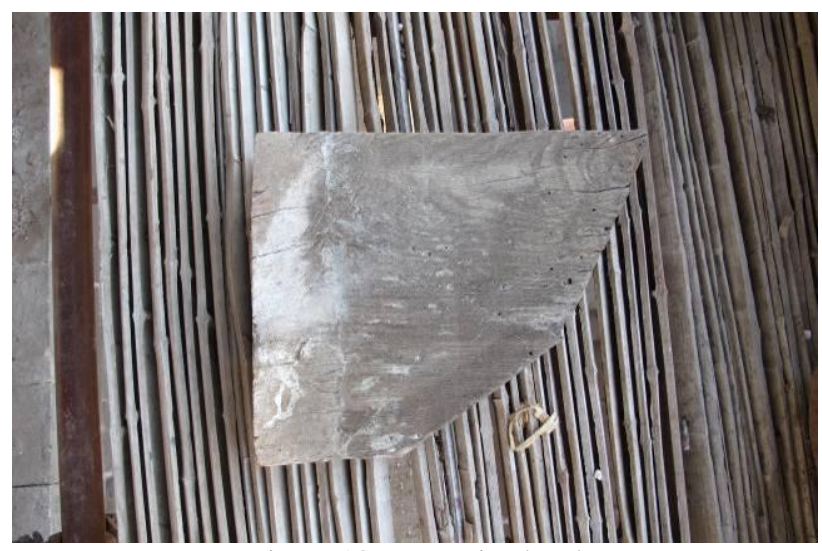

Figure 13 Decorative head 


\section{D DIGITAL MODEL DATABASE FOR WOODEN CONSTRUCTION}

In the currently practice, we still rely on traditional recording system in built heritage conservation and study. We read information from labelled drawings, photos record and textbased descriptions. As described above are based on the twodimensional expression, such an approach for a relatively simple structure is applicable. But heritage buildings with complex structure in spatial, such as traditional wooden construction in China, can not be expressed fully and accurately on the detailed information. And the traditional recording means have shortages at quantitative statistics and comprehensive analysis, some certain characteristic of wooden construction hidden in a lot of information can not be find out. Damaging assessment rely on experience and intuition because lack of comprehensive analysis on a large number of components information.

Two-dimensional database that we have set up as described before meet certain data analysis and research needs. However, what we are concerned about is three-dimensional entity combined into a complex spatial construction; it is still not sufficient to analysis in graphic form, especially for traditional wooden construction and buildings of similar kind. Even with a very strong imagination of space, it is difficult for a person to get a comprehensive understanding from a large number of components information data.

Consequently, we developed 3D Digital Model Database base on the two-dimensional database. We concentrate our forces on the wooden structure of construction which have the highest value of these heritage buildings. Linked wooden structure virtual space model with the database of wooden construction, we can express information of the database by spatial pattern. The 3D Digital Model Database combined spatial and graphical representation into one, and expressed the results of comprehensive records in the most intuitive way. Further more, it is possible to develop a lot of function such as statistical analysis of the information in spatial dimension. Our goal of the 3D Digital Model Database for wooden construction is to fully demonstrate the earlier wooden constructions information of all aspect that we have collected through the recording system in implementation process, setup long-term and effective monitoring of health status for these precious cultural heritage, and provide data for the relevant science studies and research tools especially in architectural history of China.

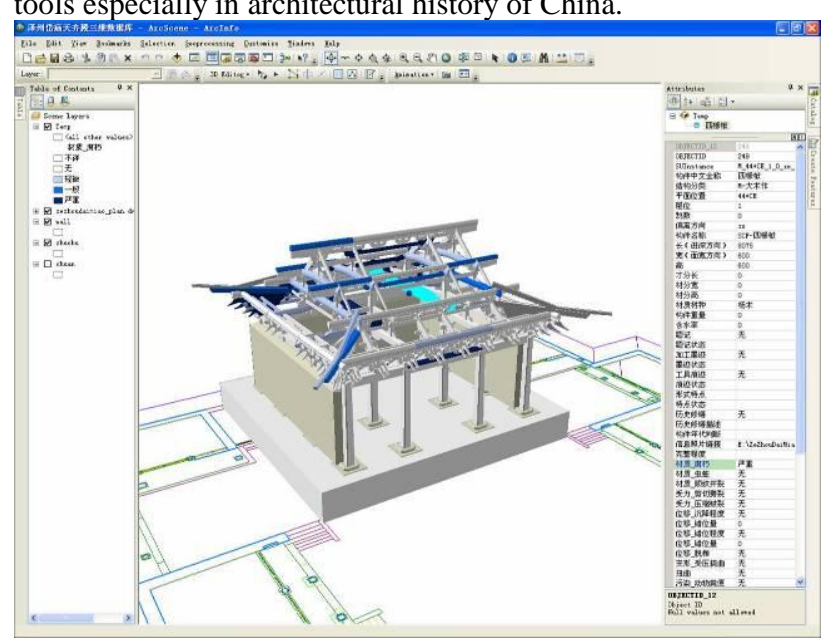

Figure 14 3D Digital Model Database based on ArcGIS.
To setup the 3D Digital Model Database, the first step is to create a virtual space model for the wooden structure. We have tried a variety of parametric modelling software such as Autodesk Revit Architecture, but found that it is hard to describe the wood member's shape in standard spatial parameter. So we chose a simpler modelling software-Google Sketchup. It is easy to create different shape in Sketchup especially the tenon-andmortise work. In the Sketchup model of wooden structure, each wood member is created as a component and be assigned a unique name. After that, the Sketchup model was transformed into ArcGIS according to geographic coordinates. The component with unique name in Sketchup changed into multipatch with the same name in ArcGIS. And because the ArcGIS backstage support database have the same data files with the database we have setup by $S Q L$ before, we can relate the information data of wood members to the multipatch in ArcGIS. With the powerful data presentation and analysis capabilities of ArcGIS, we can get a 3D Digital Model Database of traditional wooden structure.

Compared with traditional drawing information labelling, 3D Digital Model Database is advanced in display and dissemination. We can easily observe the 3D digital model of wood structure from all angles, not only the structural relationship of the wooden construction and their components spatial scales, but also material, damaged, age, maintenance and replacement, painting, inscriptions, and other specific information. It can facilitate data access and filtration in a complex structure. For example, we can highlight component which has historic inscription. After that, we can click on the multipatch to call up the information pop-up, and we can find the contents of these inscriptions and related photos.

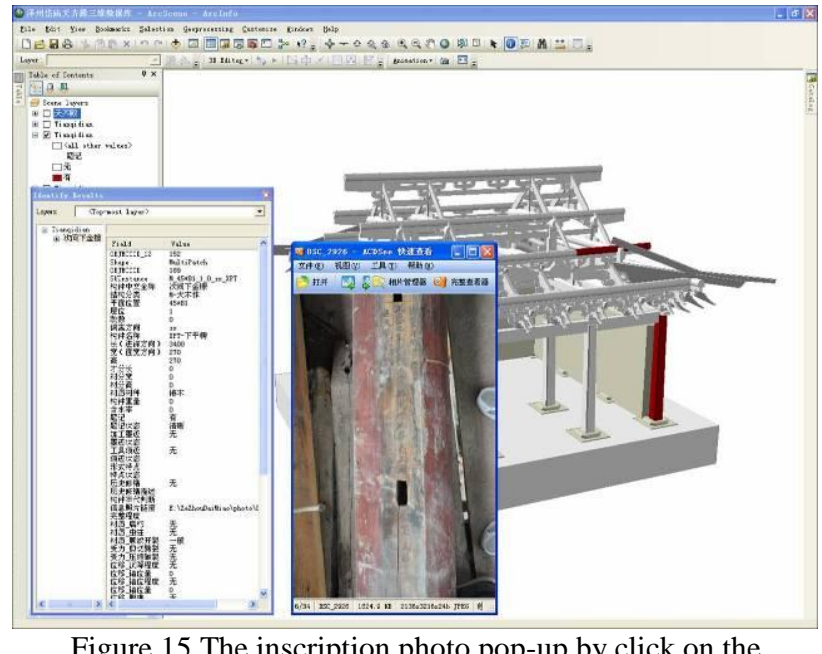

Figure 15 The inscription photo pop-up by click on the multipatch in database.

Large amounts of data can be expressed to screen in a spatial visualized way through 3D Digital Model Database. Figure 16 shows timber species of wood structure of Tianqi Shrine in Zezhou Dai Miao Temple, South of Shanxi province. When materials are reflected in the three-dimensional database, we can see the wood members of "dou gong" on the top of corner column, where stress concentrated on this region inside the structure, were made by pagoda tree wood (Sophora sp., Fabaceae) that is hard in wood property. The wood members of "dou gong" on the top of south facade column were made by oak (Quercus sp., Fagaceae) that is good in wood property. And the rest part of "dou gong" were made by cottonwood (Populus sp., Salicaceae) whose fibre is loose and is relatively not good 
in wood property. Through visualized spatial observe, we can easily discover the craftsman's idea in material use, and even the material change in historic preservation.

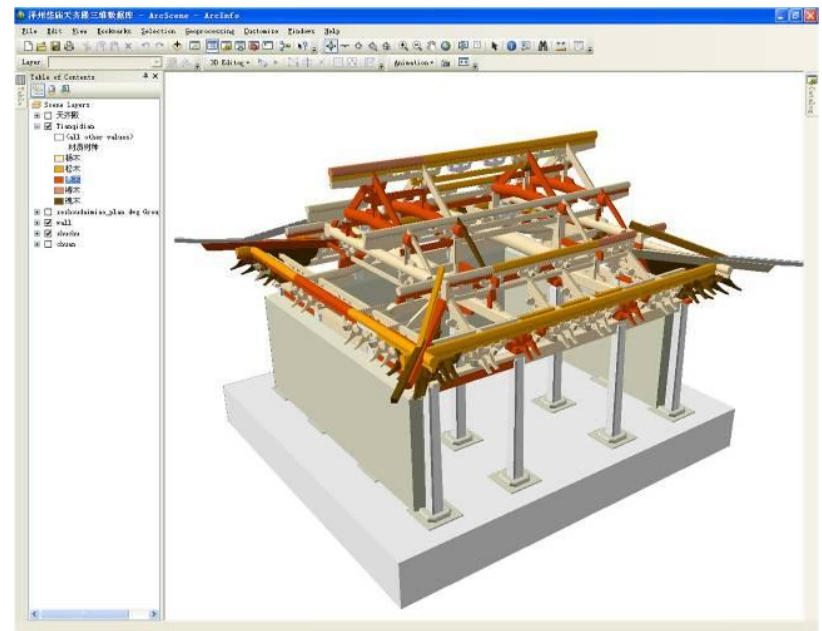

Figure 16 Timber species of wood structure of Tianqi Shrine

We can make use of the 3D Digital Model Database to do some interesting statistics analysis, which let us have a better understanding of the wooden construction. For example, we divide the wood members of Tianqi Shrine into five levels according to the length, from dark to light represents members from long to short. Statistics results are visually showed that, in these hundreds of wood members, only four of them are longer than 5 meters. Most of the components are short timber compared to the big size of the building. This fact reflects a very important feature of the early wooden construction in southern Shanxi, craftsman make full use of the limited length of timber to create a space as large as possible, and a strong beautiful and durable construction at the same time.

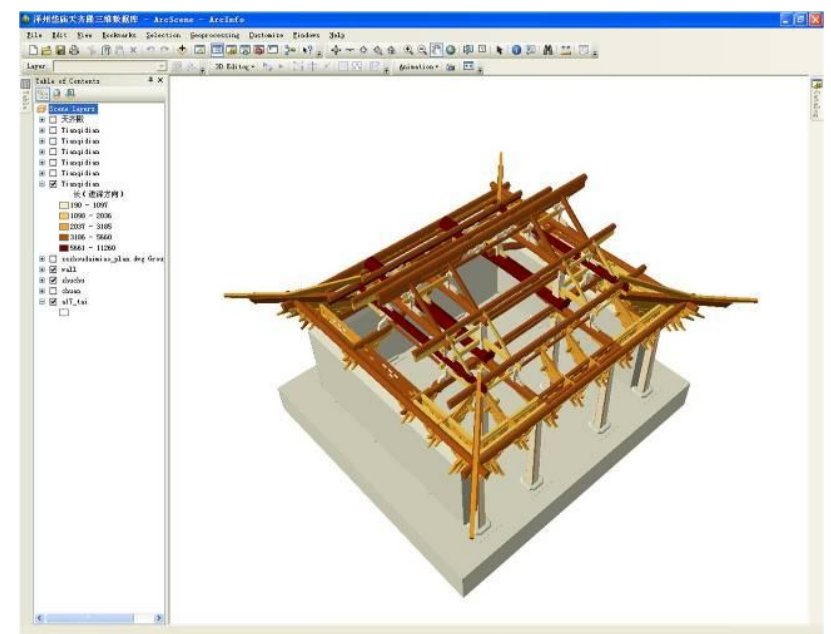

Figure 17 Statistics results of wood members length of Tianqi Shrine

The 3D Digital Model Database can also help us in damage assessment. Figure 18 shows decay degree of wood members of Tianqi shrine. From this three-dimensional graph, we can see that the wood members of back facade are much more dangerous than front facade, especially at the corner. We can see which components of the wooden construction were intervene and which components were replaced through this restoration by the database.
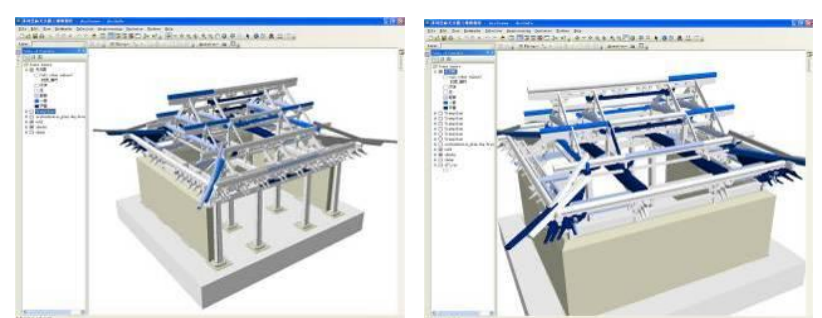

Figure 18 Decay degree of wood members of Tianqi shrine.

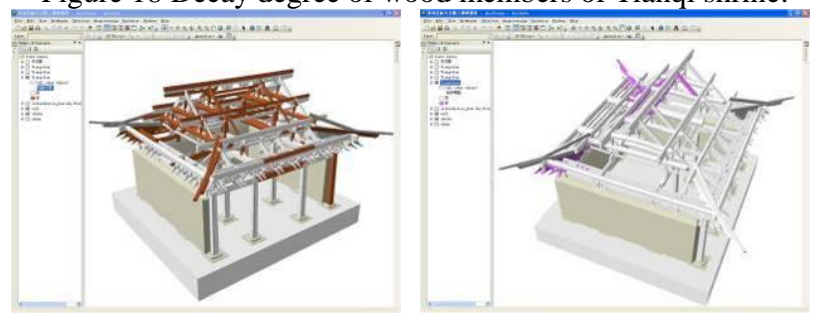

Figure 19 The wood members be intervened (left) and replaced (right) through Tianqi shrine restoration.

\section{AN ANSWER}

The Early Wooden Construction in southern Shanxi Province are extremely valuable cultural resources. One of the long-term goals of this documentation and information management project is to assist in the conservation and research of these resources. The 3D Digital Model Database helps us set up an integrate information inventory for wooden structure with their similar types in China, and; makes it much easier to carry out survey of these structures at any stage for the purpose of structure monitor. Large amounts of data in the wooden structure can be intuitively expressed graphically to show its spatial distribution; and we can make comprehensive assessment of the component group by observe the spatial pattern, or evaluate the whole building damage through the database.

An Internet application is being planned to assist in disseminating the 3D Digital Model Database to the public and to professionals who study these buildings. The most interesting is, with the development of mobile terminal equipment, the 3D Digital Model Database of Wooden Structure can be displayed in virtual exhibition easily via the internet by them.

\section{REFERENCES:}

Rand Eppich, editor; Amel Chabbi, associate editor, 2011. Recording, documentation, and information management for the conservation of heritage places: illustrated examples. The Getty Conservation Institute, Los Angeles, pp. 167-173. 